\title{
Study of the Optical Properties of Functionalized Gold Nanoparticles in Different Tissues and Their Correlation with the Temperature Increase
}

\author{
A. Carrillo-Cazares, ${ }^{1,2}$ N. P. Jiménez-Mancilla, ${ }^{1,2,3}$ M. A. Luna-Gutiérrez, ${ }^{1}$ \\ K. Isaac-Olivé, ${ }^{2}$ and M. A. Camacho-López ${ }^{4}$ \\ ${ }^{1}$ Departamento de Materiales Radiactivos, Instituto Nacional de Investigaciones Nucleares, 52750 Ocoyoacac, MEX, Mexico \\ ${ }^{2}$ Facultad de Medicina, Universidad Autónoma del Estado de México, 50180 Toluca, MEX, Mexico \\ ${ }^{3}$ CONACyT, Instituto Nacional de Investigaciones Nucleares, 52750 Ocoyoacac, MEX, Mexico \\ ${ }^{4}$ Laboratorio de Fotomedicina, Biofotónica y Espectroscopía Láser de Pulsos Ultracortos, Facultad de Medicina, \\ Universidad Autónoma del Estado de México, 50180 Toluca, MEX, Mexico
}

Correspondence should be addressed to N. P. Jiménez-Mancilla; nallely_jimenez@yahoo.com.mx

Received 7 June 2017; Accepted 20 September 2017; Published 6 November 2017

Academic Editor: Ajayan Vinu

Copyright (C) 2017 A. Carrillo-Cazares et al. This is an open access article distributed under the Creative Commons Attribution License, which permits unrestricted use, distribution, and reproduction in any medium, provided the original work is properly cited.

Mie theory explains the interaction of light with a gold nanoparticle (AuNP) through the absorption $\left(C_{\text {abs }}\right)$, scattering $\left(C_{\text {sca }}\right)$, and extinction $\left(C_{\text {ext }}\right)$ cross sections. These parameters have been calculated in the case of AuNPs dispersed in homogeneous media, but not for specific tissues. The aim of this research was to theoretically obtain the optical cross sections $\left(C_{\mathrm{abs}}, C_{\mathrm{sca}}\right.$, and $\left.C_{\text {ext }}\right)$ of functionalized AuNPs in liver and colon tissues through Mie theory and correlate them with the temperature increase observed experimentally in tissues containing AuNPs under plasmonic photothermal irradiation using a Nd-YAG laser $(\lambda=532 \mathrm{~nm})$. Calculations showed that $C_{\text {abs }}$ represents $98.96 \pm 0.03 \%$ of $C_{\text {ext }}$ at $532 \mathrm{~nm}$. The $C_{\text {ext }}$ value for a functionalized AuNP in water was $365.66 \mathrm{~nm}^{2}$ ( $94 \%$ of the theoretical maximum value at $\left.522.5 \mathrm{~nm}\right), 404.24 \mathrm{~nm}^{2}$ in colon $(98 \%$ of the theoretical maximum value at $525 \mathrm{~nm}$ ), and $442.39 \mathrm{~nm}^{2}$ in liver (96\% of the theoretical maximum value at $525 \mathrm{~nm}$ ). Therefore, nanoparticles irradiated at $532 \mathrm{~nm}$ are very close to their resonance value. These results correlated with the experimental irradiation of functionalized AuNPs in different tissues, where the average temperature increase showed the pattern liver $>$ colon $>$ water. The temperature increase observed ( $\Delta T$ up to $13^{\circ} \mathrm{C}$ ) is sufficient to produce cellular death.

\section{Introduction}

The optical properties (absorption and scattering) present in gold nanoparticles (AuNPs) play a significant role in the development of new photothermal ablation systems potentially applicable in cancer treatment [1-3]. The photothermal ablation process generated by AuNPs is due to the optical absorption phenomenon present when AuNPs are exposed to light that induces a collective oscillation of the free electrons (surface plasmon resonance, SPR) $[1,4-6]$. The temperature around the AuNPs reaches $800^{\circ} \mathrm{C}$ and causes irreversible thermal destruction to the tissue [7-11].
Gold nanoparticles (AuNPs) have been synthesized in various sizes and shapes, for instance, spheres, rods, cubic, and prisms forms $[12,13]$. Some of these structures have been proposed for a variety of medical applications $[2,3,14,15]$. Many biomolecules such as DNA chains, proteins, peptides, and aptamers can be conjugated to one AuNP [3]. The ArgGly-Asp (RGD) sequence has been reported to have high affinity and selectivity for the $\alpha(v) \beta(3)$ integrin. This integrin is expressed on the surface of healthy endothelial cells at low levels but is overexpressed in the tumor neovasculature of osteosarcoma, neuroblastoma, glioblastoma, melanoma, lung carcinoma, and breast cancer [16-19]. 
The SPR band intensity and wavelength characteristics of the AuNPs depend on factors affecting the electron charge density on the particle surface, such as the metal type, particle size, shape, structure, composition, and the dielectric constant of the surrounding medium (water, type of tissue). In the SPR phenomenon, the electrons of gold resonate in response to incoming radiation, causing both the absorption and scattering of light; these processes can be explained by Mie theory. This approach provides exact analytical solutions to Maxwell's equations for spheres with various diameters; the absorption and scattering probabilities are represented by the absorption, scattering, and extinction cross sections $\left(C_{a b s}\right.$, $C_{\text {sca }}$, and $C_{\text {ext }}$ ) [13]. The optical absorption and scattering phenomena strongly depend on the size of the nanoparticles and the dielectric constant of the surrounding medium. For small AuNPs in water (refractive index $n=1.33$ and dielectric constant $\varepsilon=n^{2}$ ), total extinction is completely ruled by absorption; when the size increases, the scattering process appears and intensifies [20-23].

The theoretical calculations of the $C_{\mathrm{abs}}, C_{\mathrm{sca}}$, and $C_{\text {ext }}$ coefficients through Mie theory have been previously reported in the case of light interacting with AuNPs dispersed in a homogeneous medium, where the refractive index is considered a constant. However, such parameters have not been determined for specific tissues, where the refractive index has to be evaluated as a function of the interacting wavelength since the absorption and scattering cross sections are strongly affected by the composition of the tissue (amount of the water, hemoglobin, and melanin). The determination of these parameters could explain the temperature increase generated by the AuNP, which is a critical point in the potential clinical application of the plasmonic photothermal therapy.

This research aimed to calculate the optical coefficients $\left(C_{\text {abs }}, C_{\text {sca }}\right.$, and $\left.C_{\text {ext }}\right)$ of functionalized gold nanoparticles in different tissues (liver and colon) by Mie theory and to determine their correlation with the temperature increase observed experimentally in tissues containing AuNPs under plasmonic photothermal irradiation using a Nd-YAG laser.

\section{Materials and Methods}

2.1. Materials. Gold nanoparticles $(20 \mathrm{~nm})$ were obtained from Sigma-Aldrich $\left(6.54 \times 10^{11}\right.$ particles $\left./ \mathrm{mL}\right)$. A $50 \mu \mathrm{M}$ solution of $\mathrm{c}[\mathrm{RGDfK}(\mathrm{C})]$ and $\mathrm{PBS} \mathrm{pH} 7$ was prepared in type I grade water. Homogeneous suspensions of pork liver and chicken intestinal viscera (for simulating colon tissue) were blended with a small volume of water. The mixtures were then passed through a strainer for sieving and homogenization.

2.2. Preparation of the AuNP-c[RGD $f K(C)]$ Conjugate. The synthesis of cyclo[Arg-Gly-Asp-Phe-Lys(Cys)] (c[RGDfK(C)]) was carried out according to the method reported by FerroFlores et al. [14]. In the $\mathrm{c}[\mathrm{RGDfK}(\mathrm{C})]$ molecule, the sequence Arg-Gly-Asp-(-RGD-) acts as the active biological site. The $\mathrm{D}$-Phe (f) and Lys (K) residues completed the cyclic and the pentapeptide structure, and Cys (C) is the spacer that contains the active thiol group that interacts with the gold nanoparticle surface. For conjugate preparation, a $50 \mu \mathrm{M}$ solution of $\mathrm{c}[\mathrm{RGDfK}(\mathrm{C})]$ was prepared using type I grade water, and then $0.02 \mathrm{~mL}\left(6.023 \times 10^{14}\right.$ molecules $)$ was added to $1 \mathrm{~mL}$ of the AuNP suspension $\left(20 \mathrm{~nm}, 6.54 \times 10^{11}\right.$ particles $/ \mathrm{mL}$ ) followed by stirring for $5 \mathrm{~min}$. No further purification was required.

2.3. Characterization before and after Laser Irradiation. Before laser irradiation, the chemical conjugation was confirmed by UV-Vis, medium- and far-IR, Raman spectroscopy, and Transmission Electron Microscopy (TEM), as previously reported $[16,19]$.

After laser irradiation, TEM and the absorption spectrum in the range of $400-800 \mathrm{~nm}$ were also obtained. The UVVis analysis was performed with a Perkin-Elmer Lambda-Bio spectrometer using a $1 \mathrm{~cm}$ quartz cuvette to monitor the size and the AuNP surface plasmon band around $520 \mathrm{~nm}$.

\subsection{Absorption Cross Section Evaluation}

2.4.1. Complex Dielectric Constant. The complex dielectric constant $\left(\varepsilon_{p}=\varepsilon_{p}^{\prime}+i \varepsilon_{p}^{\prime \prime}\right)$ of the AuNP was obtained from the complex refractive index of gold $\left(\widetilde{n_{p}}=n_{p}+i k_{p}\right)$ at different wavelengths (450 to $700 \mathrm{~nm}$ ), according to Werner et al. [20]. These values were corrected by the nanoparticle size using a cubic interpolation and calculated as

$$
\widetilde{n_{p}}=n_{p}+i k_{p} \text {. }
$$
follows:

The complex dielectric constant $\varepsilon_{p}^{\prime}+i \varepsilon_{p}^{\prime \prime}$ was obtained as

$$
\begin{aligned}
& \varepsilon_{p}=\left(\widetilde{n_{p}}\right)^{2}=\left(n_{p}+i k_{p}\right)^{2} \\
& \varepsilon_{p}=\left(n_{p}\right)^{2}-\left(k_{p}\right)^{2}+i 2\left(n_{p} * k_{p}\right),
\end{aligned}
$$

where

$$
\begin{aligned}
& \varepsilon_{p}^{\prime}=\left(n_{p}\right)^{2}-\left(k_{p}\right)^{2} \\
& \varepsilon_{p}^{\prime \prime}=2\left(n_{p} * k_{p}\right) .
\end{aligned}
$$

For the $\varepsilon_{m}$ media (liver or colon tissue), the complex dielectric constants were obtained following the same procedure employed for AuNP but using the complex index reported by Giannios et al. [22, 23]. The experimental data was used to obtain the values for the refractive index as a continuous function dependent on the wavelength.

2.4.2. Calculations of Optical Properties of AuNP-RGD-Tissue by the Mie Theory. Theoretical calculations were carried out using the generalized Mie theory considering spherical nanoparticles ( $r=20 \mathrm{~nm}$ ) whose diameter is lower than the irradiation wavelength $(532 \mathrm{~nm})$. In this case, the Mie-Drude theory was not employed. Therefore, free electron density was not directly considered. However, electron movement is taken into account indirectly in the dielectric functions of materials.

Mie theory explains the interaction between the light and AuNPs where the absorption and scattering probabilities 


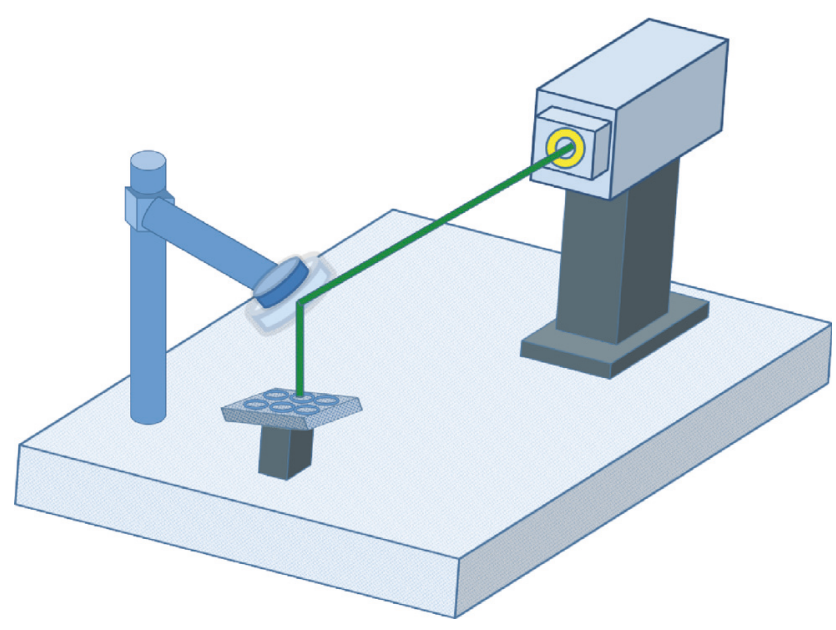

FIGURE 1: Laser arrangement.

process are represented by the absorption cross section $C_{\text {abs }}$ $\left(\mathrm{m}^{2}\right)$, the scattering cross section $C_{\mathrm{sca}}\left(\mathrm{m}^{2}\right)$, and the extinction cross section $C_{\text {ext }}$, which is the sum of both $\left(C_{\text {ext }}=C_{\text {sca }}+\right.$ $C_{\text {abs }}$ ). These cross sections were calculated as follows:

$$
\begin{aligned}
& C_{\text {ext }}=\frac{24 \pi^{2} R^{3} \varepsilon_{m}{ }^{3 / 2}}{\lambda} * \frac{\varepsilon_{p}^{\prime \prime}}{\left(\varepsilon_{p}^{\prime}+2 \varepsilon_{m}\right)^{2}+\varepsilon_{p}^{\prime \prime 2}} \\
& C_{\text {sca }}=\frac{2^{7} \pi^{5} R^{6}}{\lambda} *\left|\frac{\varepsilon_{p}^{\prime}-\varepsilon_{m}}{\varepsilon_{p}^{\prime}+2 \varepsilon_{m}}\right|^{2} \\
& C_{\text {abs }}=C_{\text {ext }}-C_{\text {sca }},
\end{aligned}
$$

where $R$ is the radius of the particle and $\lambda$ is the incident wavelength.

All the calculations were carried out considering the real and imaginary parts of the dielectric constant of the AuNP and tissue.

2.5. Laser Arrangement. Laser experiments were conducted using an Nd-YAG laser (Qsmart-100, Quantel laser) pulsed for $5 \mathrm{~ns}$ at $532 \mathrm{~nm}$ (energy $=45.9 \mathrm{~mJ} /$ pulse), with a repetition rate of 5,10 , and $15 \mathrm{~Hz}$. The power of each laser pulse was measured by a Dual-Channel Joulemeter/Power Meter (Molectron EPM 200, Coherent). A diverging lens was used in the path of the laser beam in a way that the well plate was fully covered by the laser (diameter $=7 \mathrm{~mm}$; area $=0.38 \mathrm{~cm}^{2}$ ) (Figure 1). The well plate was placed on a heating plate at $37^{\circ} \mathrm{C}$ (Microplate Thermo Shaker, Human Lab MB100-2A, Hangzhou Zhejia, China) during laser irradiation.

2.5.1. Laser Irradiation Experiments. The effect of laser irradiation on the temperature increasing rate was measured in the following treatments:

(a) Control (200 $\mu \mathrm{L}$ of type I grade water or $200 \mu \mathrm{L}$ of PBS $\mathrm{pH} 7)$

(b) $100 \mu \mathrm{L}$ liver tissue and $100 \mu \mathrm{L}$ of control solution (c) $100 \mu \mathrm{L}$ colon tissue and $100 \mu \mathrm{L}$ of control solution

(d) $100 \mu \mathrm{L}$ of AuNP-c[RGDfK(C)] and $100 \mu \mathrm{L}$ of control solution

(e) $100 \mu \mathrm{L}$ liver tissue and $100 \mu \mathrm{L}$ of AuNP-c[RGDfK(C)]

(f) $100 \mu \mathrm{L}$ colon tissue and $100 \mu \mathrm{L}$ of AuNP$c[\operatorname{RGDfK}(\mathrm{C})]$.

The described treatments were exposed individually to the laser $(n=6)$. The temperature was measured using a type $\mathrm{K}$-thermocouple (model TPK-01) of immediate reaction that had been previously calibrated (probe diameter $=0.8 \mathrm{~mm}$ ). A thermocouple was introduced into the well plate, and the temperature was registered every single second using a coldjunction-compensated K-thermocouple fixed to a digital converter (MAX6675, Maxim Integrated TM) connected to a microcontroller board (Arduino Uno) with a USB computer connection.

The total delivered energy $\left(\mathrm{DE}_{m}, \mathrm{~J} / \mathrm{cm}^{2}\right)$ to the well plate was calculated as follows:

$$
\mathrm{DE}_{m}=\mathrm{DP}_{m} * t,
$$

where $t$ is the irradiation time and $\mathrm{DP}_{m}$ is the irradiance or density power in $\mathrm{W} / \mathrm{cm}^{2}$ and is calculated by

$$
\mathrm{DP}_{m}=\frac{P_{m}}{A},
$$

where $P_{m}$ is the average power $\left(P_{m}=E * f\right), f$ is the repetition rate in $\mathrm{Hz}, E$ is the energy by pulse in Joule/pulse, and $A$ is the irradiation area in $\mathrm{cm}^{2}$. The density power $\mathrm{DP}_{m}$ was kept constant at $0.65 \mathrm{~W} / \mathrm{cm}^{2}$ for each irradiation time point $(6.5$, 3.5 , and $1.5 \mathrm{~min}$ ) which corresponds to the 5,10 , and $15 \mathrm{~Hz}$ frequencies, respectively $[8,24]$.

2.6. Statistical Analysis. Differences among treatment data were evaluated with Student's $t$-test (grouped analysis; significance was defined as $p<0.05$ ).

\section{Results and Discussion}

\subsection{Characterization before and after Laser Irradiation}

3.1.1. Before Laser Irradiation. Spectroscopy techniques and TEM images demonstrated that AuNPs were functionalized with the $c[\operatorname{RGDfK}(\mathrm{C})]$ peptide accordingly with previous reports $[16,19]$. The average particle diameter was $21.56 \pm$ $0.06 \mathrm{~nm}$.

The UV-Vis spectrum showed the surface plasmon resonance band at $520 \mathrm{~nm}$ for AuNPs, and a red shift to $522 \mathrm{~nm}$ for AuNP-c[RGDfK(C)] was observed. This shifting is attributed to the changes in the refraction index as a consequence of the interaction between the peptide and the AuNP surface [16].

Raman spectroscopy and medium- and far-infrared showed several well-defined bands characteristics of the AuNP-c[RGDfK(C)] conjugate [16]. The Far-IR spectrum of the AuNP-c[RGDfK(C)] showed a characteristic band at $279 \pm 1 \mathrm{~cm}^{-1}$, which is representative of the $\mathrm{Au}-\mathrm{S}$ bond $[18,19]$. 

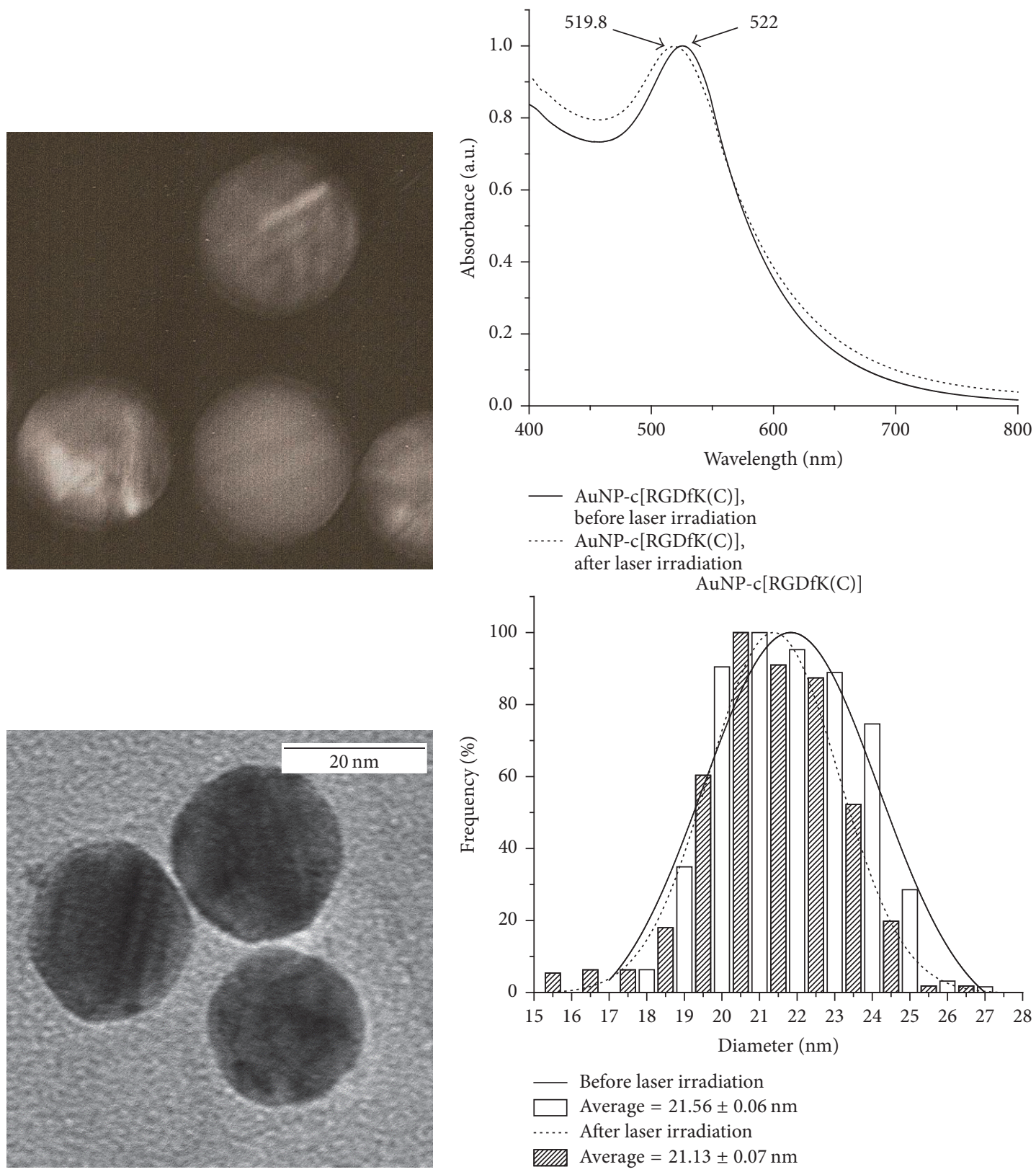

FIGURE 2: Morphological results before and after laser irradiation.

3.1.2. After Laser Irradiation. TEM images after laser irradiation demonstrated that the $[\operatorname{RGDfK}(\mathrm{C})]$ peptide remains functionalized to AuNPs surface. The particle average diameter changes from $21.56 \pm 0.06 \mathrm{~nm}$ to $21.13 \pm 0.07 \mathrm{~nm}$ (Figure 2). The observed size modification after laser irradiation on AuNP citrate-stabilized was from $20 \pm 1.6 \mathrm{~nm}$ to $19.38 \pm 0.02 \mathrm{~nm}$, which can be explained as a consequence of molecular steric rearrangement on the nanoparticle surface.

TEM measurements were supported by SPR band on UVVis spectra. The SPR for AuNP-c[RGDfK(C)] shifted from $522 \mathrm{~nm}$ to $519.8 \mathrm{~nm}$ after irradiation, while for AuNP the shifting was from $520 \mathrm{~nm}$ to $517.5 \mathrm{~nm}$ (Figure 2). These shifts to a lower wavelength are also an indication of a reduction in the nanoparticle size.

\subsection{Absorption Cross Section Evaluation}

3.2.1. Complex Dielectric Constant. Figure 3 shows the differences between the real and imaginary parts of the refractive index and dielectric constant of (a) gold, (b) liver tissue, and (c) colon tissue. The real part of the dielectric constant is related to the stored energy, and the imaginary part is related to the dissipation of the energy within the medium.

3.3. Optical Coefficients of AuNP-RGD-Tissue by the Mie Theory. In agreement with previous reports $[1,4]$ the results shown in this research demonstrated that $C_{\text {ext }}$ is mainly due to the absorption process contribution (Figure 4). The effective absorption section represents the $98.96 \pm 0.03 \%$ of 

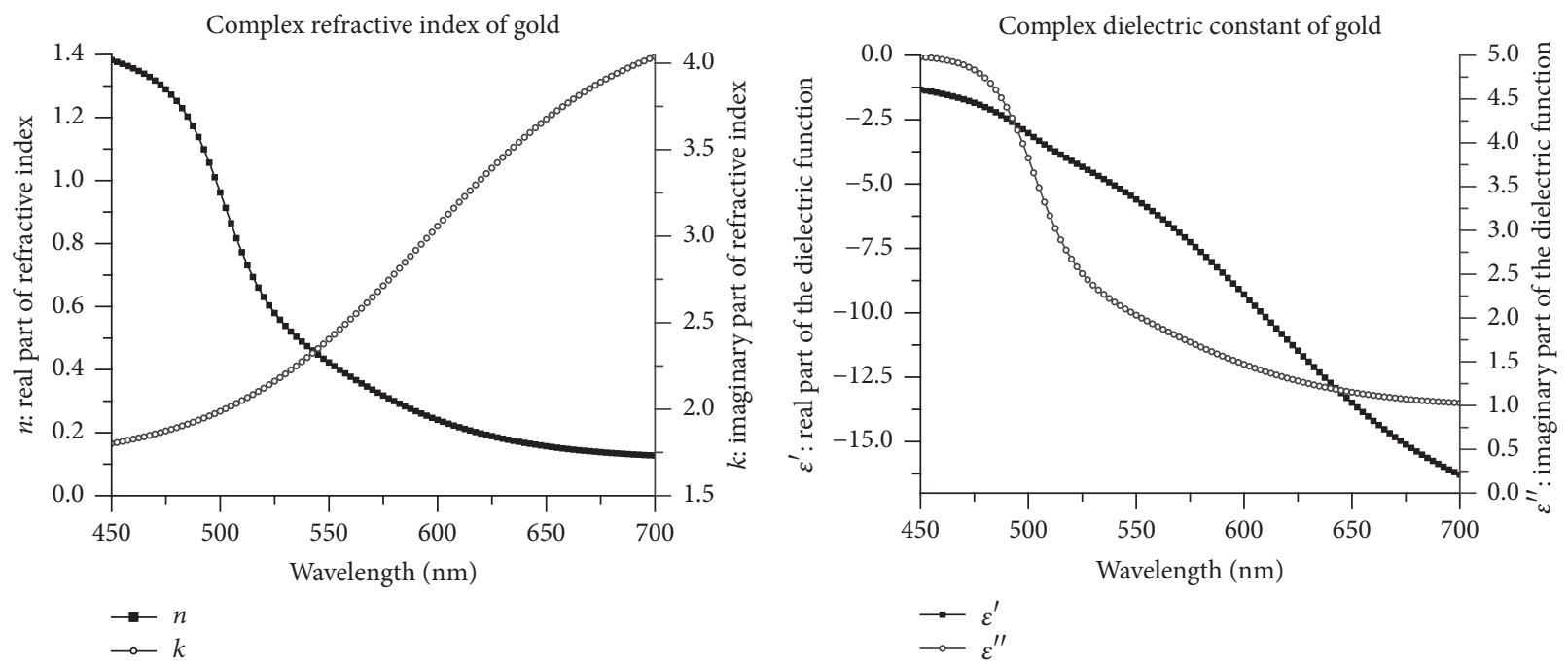

(a)
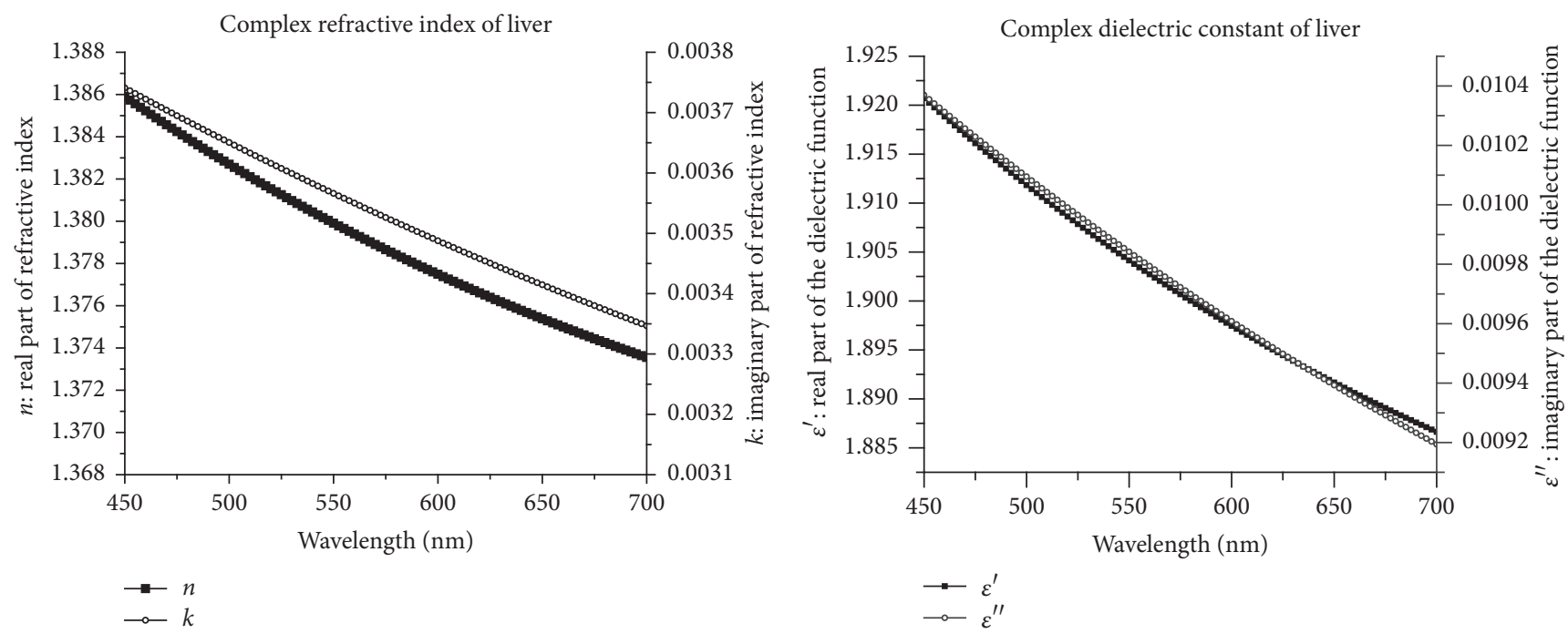

(b)
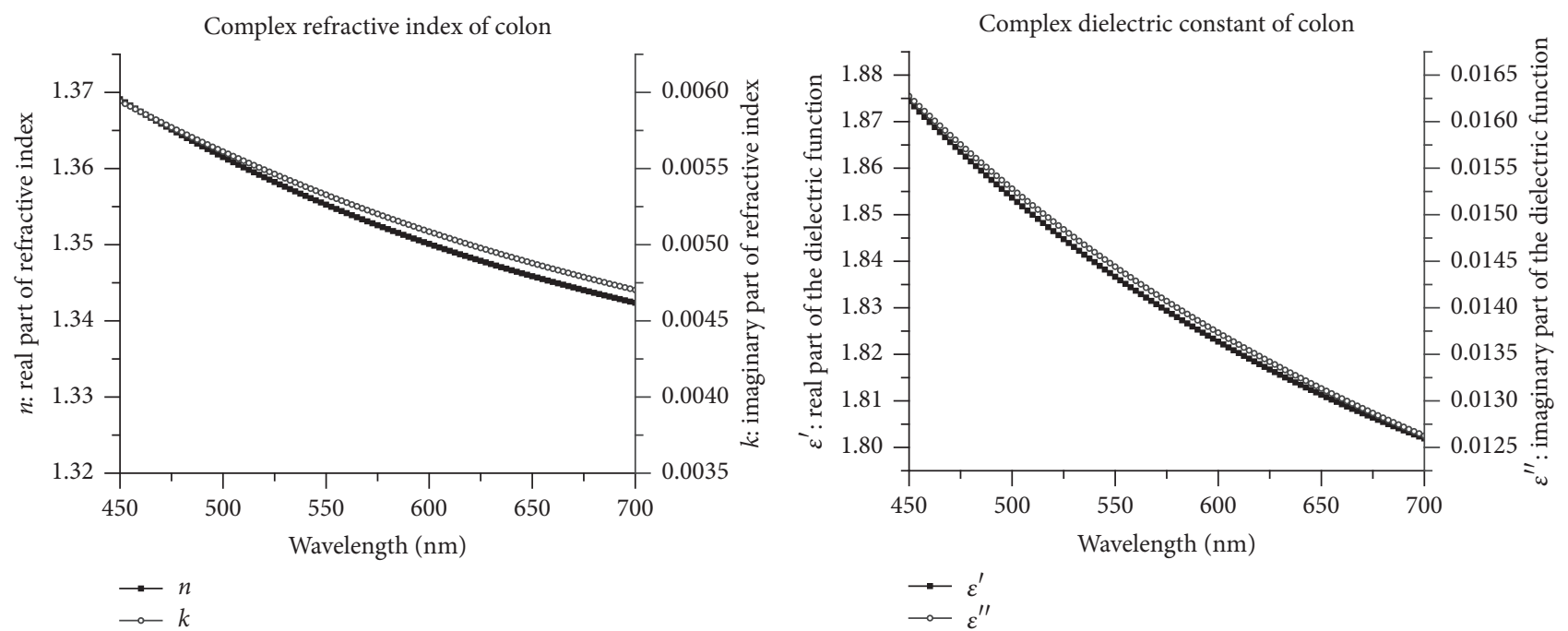

(c)

FIGURE 3: Real and imaginary parts of the refractive index $(n, k)$ and dielectric constant $\left(\varepsilon^{\prime}, \varepsilon^{\prime \prime}\right)$ of the (a) gold, (b) liver tissue, and (c) colon tissue. 


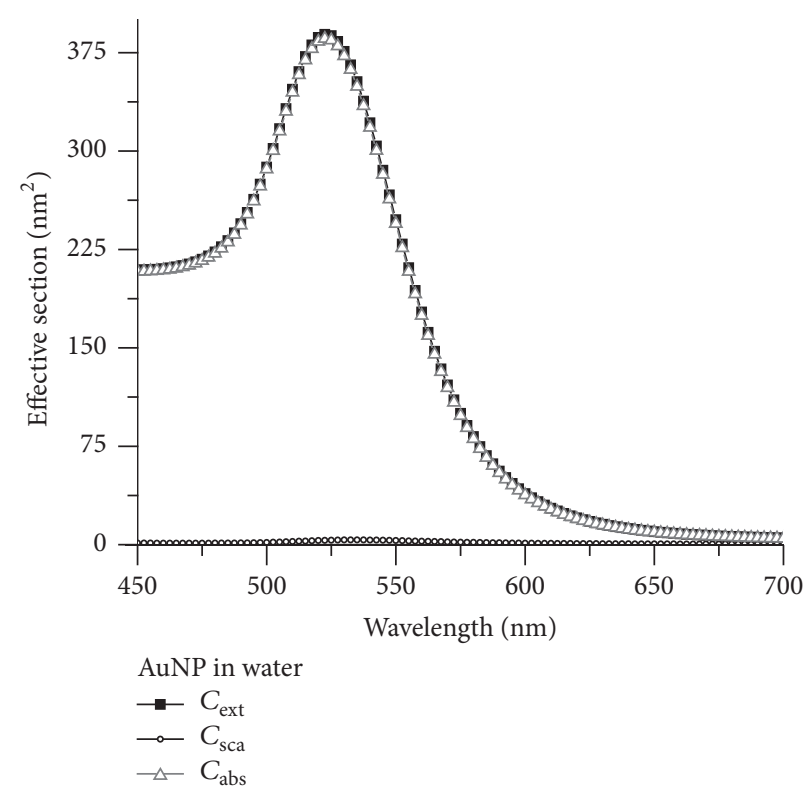

(a)

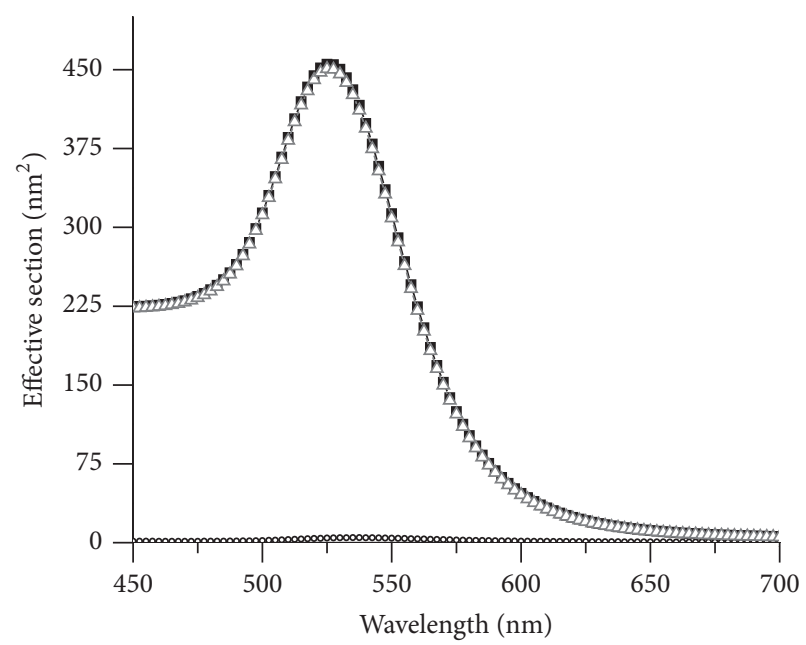

AuNP in liver tissue

$\rightarrow C_{\text {ext }}$
$\multimap C_{\text {sca }}$
$\neg C_{\text {abs }}$

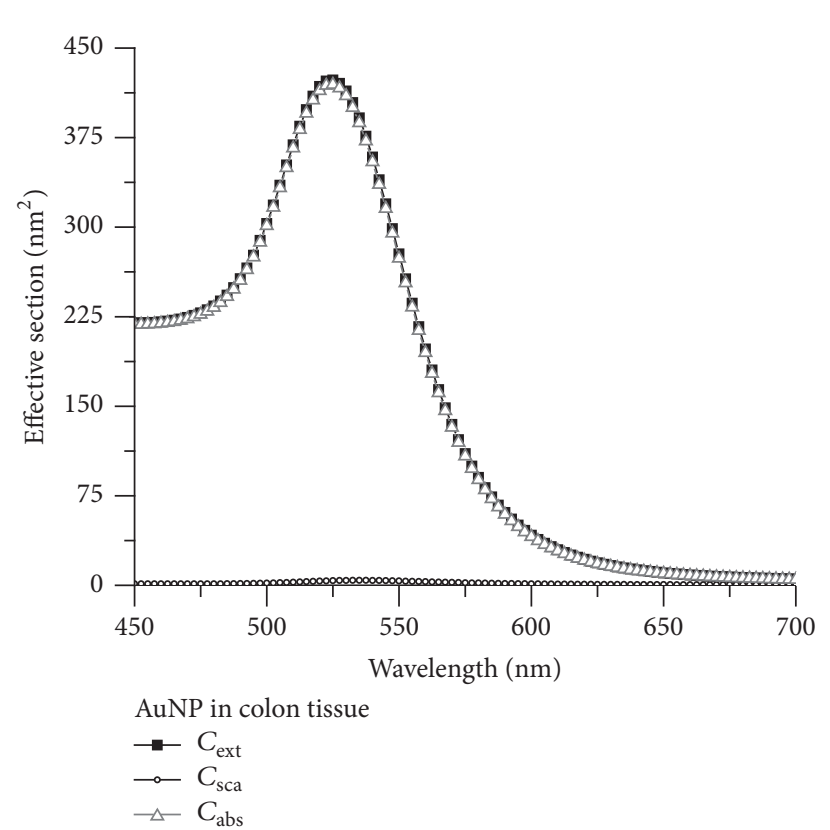

(b)

(c)

FIgURE 4: Cross section absorption, scattering, and extinction, for AuNP in (a) water, (b) liver tissue, and (c) colon tissue.

the total extinction effective section $\left(C_{\text {ext }}\right)$. Therefore the scattering one can be considered negligible. The maximum $C_{\text {ext }}$ value is observed at the irradiation wavelength of $522.5 \mathrm{~nm}$ for AuNP-RGD in a water medium and $525 \mathrm{~nm}$ when the nanoparticles are deposited or embedded in the tissues. This result means that the maximum energy absorption occurs at those wavelengths; consequently, the highest temperature increase rate should be reached at such wavelengths as well.

In this research, the experimental part was carried out using a $532 \mathrm{~nm}$ Nd-YAG laser. For this wavelength, the
AuNP-RGD in water $(n=1.33)$ has a $C_{\text {ext }}=365.66 \mathrm{~nm}^{2}$, while these values were 442.39 and $404.24 \mathrm{~nm}^{2}$ for AuNPRGD-liver and AuNP-RGD-colon, respectively. This result means that the irradiation of these three media containing nanoparticles would increase the temperature in the pattern liver $>$ colon $>$ water.

3.4. Laser Irradiation. The ratio between the temperature increase and the irradiation frequencies in each one of the treatments is shown in Figure 5. Except for colon tissue, 


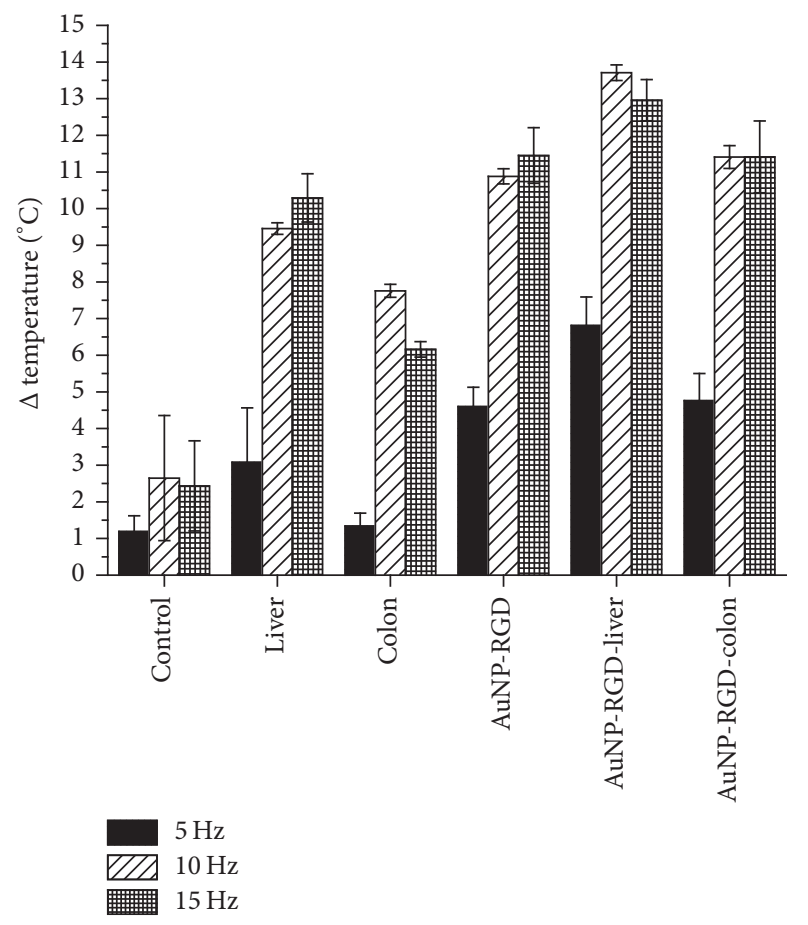

FIgURE 5: Total temperature increase versus irradiation frequency with laser.

there is no significant difference $(p<0.05)$ between the $\Delta T$ values reached with 10 or $15 \mathrm{~Hz}$. However, there are significant differences between the higher frequencies with the lowest tested $(5 \mathrm{~Hz})$. To generate the greatest amount of temperature, it is necessary that the pulse duration and repetition frequency be in the same order as the relaxation time of the SPR expansion wave, which is of femtoseconds. For the three frequencies studied, the temperature increase produced in the system AuNP-RGD-liver is significantly higher than the AuNP-RGD-colon and AuNP-RGD-water systems. These increments followed the same trend of the theoretical $C_{\text {ext }}$ calculated before.

$C_{\text {ext }}$ values obtained at $532 \mathrm{~nm}$ for AuNP-RGD in the water media, colon tissue, and liver tissue are, respectively, $94 \%, 98 \%$, and $96 \%$ of the $C_{\text {ext }}$ maximum values obtained at $522.5 \mathrm{~nm}$ and $525 \mathrm{~nm}$. In other words, the nanoparticles were irradiated with $\lambda$ very close to that of the resonance value. This incident energy reached the nanoparticle at all the tested frequencies $(5,10$, and $15 \mathrm{~Hz})$, so the higher the frequency, the higher the energy deposited in the nanoparticle. This energy deposited is absorbed at $98.96 \%$, meaning that almost all the absorbed energy is converted into heat, leading to temperature increase. Therefore, the calculation of $C_{\mathrm{ext}}, C_{\mathrm{abs}}$, and $C_{\text {sca }}$ helps in the prediction of a pattern of temperature increase when AuNP-RGD immersed in a medium is irradiated.

Figure 6 shows the total temperature increase reached in each of the treatments at the different repetition frequencies. There is no statistically significant difference between the temperature values reached by the control sample as the frequency changes. The temperature reaches a maximum and remains constant over time, which indicates that the increase in the control sample does not depend on the repetition frequency.

Holmer et al. reported that the optical absorption of liver tissue is higher than that of colon tissue because the former contains more blood irrigation than the latter [25]. Therefore, liver and colon were employed in this work as models of high and low blood irrigation tissues, respectively. Tissues showed statistically significant difference between them regarding the temperature values reached by varying the frequency. Higher temperature values are obtained with the liver $\left(\approx 13.7^{\circ} \mathrm{C}\right)$. This difference is attributed to the different hemoglobin concentration between liver and colon and agrees with the Holmer et al. results. Hemoglobin is the tissue component of greater absorbance to wavelengths close to $532 \mathrm{~nm}$. Consequently, liver tissue has higher absorption $\left(C_{\text {ext }}\right.$ and $C_{\text {abs }}$ ), and the AuNP-RGD-liver system has the highest temperature increase.

Several authors have mentioned that the local temperature near the AuNP is increased up to approximately $700-800^{\circ}$, which is lower than the fusion temperature of gold $\left(1063^{\circ} \mathrm{C}\right)[7-11]$. Therefore, a temperature increase of the order of $10^{\circ} \mathrm{C}$ at macroscopic levels could be expected. In this work, gold nanoparticles $\left(6.54 \times 10^{11} \mathrm{AuNP} / \mathrm{mL}\right)$ generated a temperature rise of approximately $13^{\circ} \mathrm{C}(200 \mathrm{~s}$ of irradiation at $10 \mathrm{~Hz}$ or after $90 \mathrm{~s}$ of irradiation at $15 \mathrm{~Hz}$ ).

If a temperature increase of $13^{\circ} \mathrm{C}$ occurs in cells or tissues above basal body temperature $\left(37^{\circ} \mathrm{C}\right)$, several processes could lead to cellular death. These processes are related to transitions of lipid phases, denaturalization of proteins, and conformational changes of RNA and DNA, among others. This is the reason why the use of AuNPs could be useful for photothermal therapy using a Nd-YAG laser at $532 \mathrm{~nm}$ because the therapy efficiency (cell death) is directly related to the amount of heat produced.

\section{Conclusions}

The calculation of $C_{\text {ext }}, C_{\text {abs }}$, and $C_{\text {sca }}$ for the AuNPRGD-water, AuNP-RGD-colon, and AuNP-RGD-liver systems helps to understand the temperature increase observed when they are irradiated with a Nd-YAG laser at $532 \mathrm{~nm}$. The temperature increase obtained (approximately $13^{\circ} \mathrm{C}$ ) is sufficient to produce cellular death by photothermal therapy.

\section{Conflicts of Interest}

The authors declare that there are no conflicts of interest regarding the publication of this paper.

\section{Acknowledgments}

This study was supported by the Mexican National Council of Science and Technology (CATEDRAS-CONACYT-ININ337 and CONACYT-SEP-CB-2014-01-242443). This research was carried out as part of the activities of the "Laboratorio Nacional de Investigación y Desarrollo de Radiofármacos, 


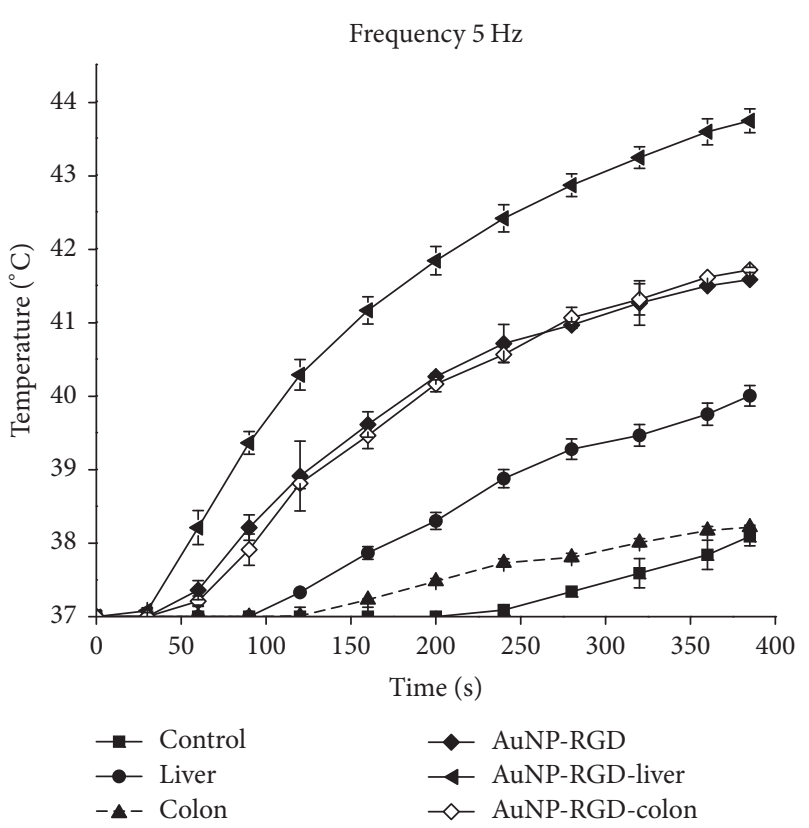

(a)

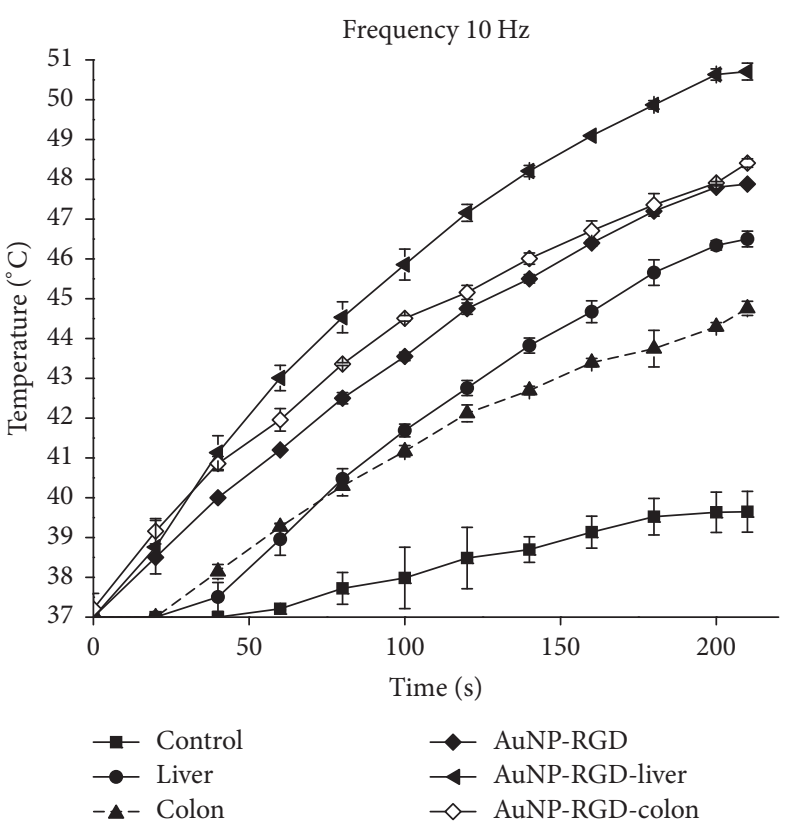

(b)

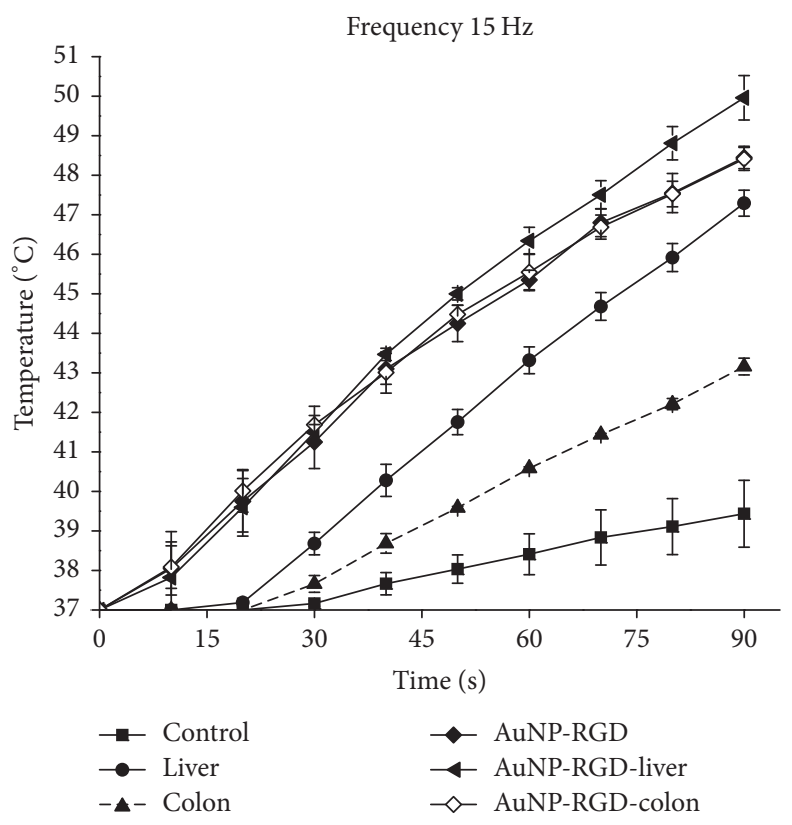

(c)

Figure 6: Temperature increase at different frequencies (a) $5 \mathrm{~Hz}$, (b) $10 \mathrm{~Hz}$, and (c) $15 \mathrm{~Hz}$.

CONACyT.” The scholarship granted to A. Carrillo-Cazares through CONACyT-PNPC program is also acknowledged.

\section{References}

[1] X. Huang and M. A. El-Sayed, "Gold nanoparticles: optical properties and implementations in cancer diagnosis and photothermal therapy," Journal of Advanced Research, vol. 1, no. 1, pp. 13-28, 2010.

[2] J. Gautier, E. Allard-Vannier, K. Hervé-Aubert, M. Soucé, and I. Chourpa, "Design strategies of hybrid metallic nanoparticles for theragnostic applications," Nanotechnology, vol. 24, no. 43, Article ID 432002, 2013.

[3] G. Ferro-Flores, C. A. de Murphy, and L. Meléndez-Alafort, "Third generation radiopharmaceuticals for imaging and targeted therapy," Current Pharmaceutical Analysis, vol. 2, no. 4, pp. 339-352, 2006.

[4] S. Hashimoto, D. Werner, and T. Uwada, "Studies on the interaction of pulsed lasers with plasmonic gold nanoparticles toward light manipulation, heat management, and nanofabrication," Journal of Photochemistry and Photobiology C: Photochemistry Reviews, vol. 13, no. 1, pp. 28-54, 2012. 
[5] R. R. Letfullin, T. F. George, G. C. Duree, and B. M. Bollinger, "Ultrashort laser pulse heating of nanoparticles: Comparison of theoretical approaches," Advances in Optical Technologies, Article ID 251718, 2008.

[6] A. Moores and F. Goettmann, "The plasmon band in noble metal nanoparticles: an introduction to theory and applications," New Journal of Chemistry, vol. 30, no. 8, pp. 1121-1132, 2006.

[7] R. R. Letfullin, C. B. Iversen, and T. F. George, "Modeling nanophotothermal therapy: Kinetics of thermal ablation of healthy and cancerous cell organelles and gold nanoparticles," Nanomedicine: Nanotechnology, Biology and Medicine, vol. 7, no. 2, pp. 137-145, 2011.

[8] H. Mendoza-Nava, G. Ferro-Flores, B. Ocampo-García et al., "Laser heating of gold nanospheres functionalized with octreotide: in vitro effect on hela cell viability," Photomedicine and Laser Surgery, vol. 31, no. 1, pp. 17-22, 2013.

[9] N. N. Nedyalkov, S. E. Imamova, P. A. Atanasov et al., "Interaction of gold nanoparticles with nanosecond laser pulses: Nanoparticle heating," Applied Surface Science, vol. 257, no. 12, pp. 5456-5459, 2011.

[10] L. Sánchez-Hernández, G. Ferro-Flores, N. P. Jiménez-Mancilla et al., "Comparative effect between laser and radiofrequency heating of rgd-gold nanospheres on MCF7 cell viability," Journal of Nanoscience and Nanotechnology, vol. 15, no. 12, pp. 98409848, 2015.

[11] X. Huang, P. K. Jain, I. H. El-Sayed, and M. A. El-Sayed, "Plasmonic photothermal therapy (PPTT) using gold nanoparticles," Lasers in Medical Science, vol. 23, no. 3, pp. 217-228, 2008.

[12] M. X. Wang, J. D. Brodin, J. A. Millan et al., "Altering DNAprogrammable colloidal crystallization paths by modulating particle repulsion," Nano Letters, vol. 17, no. 8, pp. 5126-5132, 2017.

[13] P. K. Jain, K. S. Lee, I. H. El-Sayed, and M. A. El-Sayed, "Calculated absorption and scattering properties of gold nanoparticles of different size, shape, and composition: applications in biological imaging and biomedicine," The Journal of Physical Chemistry B, vol. 110, no. 14, pp. 7238-7248, 2006.

[14] G. Ferro-Flores, B. E. Ocampo-García, C. L. Santos-Cuevas, E. Morales-Avila, and E. Azorín-Vega, "Multifunctional radiolabeled nanoparticles for targeted therapy," Current Medicinal Chemistry, vol. 21, no. 1, pp. 124-138, 2014.

[15] A. Cantelli, G. Battistelli, G. Guidetti, J. Manzi, M. Di Giosia, and M. Montalti, "Luminescent gold nanoclusters as biocompatible probes for optical imaging and theranostics," Dyes and Pigments, vol. 135, pp. 64-79, 2016.

[16] M. Luna-Gutiérrez, G. Ferro-Flores, B. Ocampo-García et al., “ ${ }^{177} \mathrm{Lu}$-labeled monomeric, dimeric and multimeric RGD peptides for the therapy of tumors expressing $\alpha(v) \beta(3)$ integrins," Journal of Labelled Compounds and Radiopharmaceuticals, vol. 55, no. 4, pp. 140-148, 2012.

[17] B. E. Ocampo-García, C. L. Santos-Cuevas, L. M. De LeónRodríguez et al., "Design and biological evaluation of 99mTcN2S2-Tat(49-57)-c(RGDyK): A hybrid radiopharmaceutical for tumors expressing $\alpha(\mathrm{v}) \beta(3)$ integrins," Nuclear Medicine and Biology, vol. 40, no. 4, pp. 481-487, 2013.

[18] A. Vilchis-Juárez, G. Ferro-Flores, C. Santos-Cuevas et al., "Molecular targeting radiotherapy with Cyclo-RGDfK(C) peptides conjugated to ${ }^{177} \mathrm{Lu}$-labeled gold nanoparticles in tumorbearing mice," Journal of Biomedical Nanotechnology, vol. 10, no. 3, pp. 393-404, 2014.
[19] E. Morales-Avila, G. Ferro-Flores, B. E. Ocampo-García, and L. M. Gómez-Oliván, "Engineered multifunctional RGD-gold nanoparticles for the detection of tumour-specific $\alpha(v) \beta(3)$ expression: Chemical characterisation and ecotoxicological risk assessment," Journal of Biomedical Nanotechnology, vol. 8, no. 6, pp. 991-999, 2012.

[20] W. S. M. Werner, K. Glantschnig, and C. Ambrosch-Draxl, "Optical constants and inelastic electron-scattering data for 17 elemental metals," Journal of Physical and Chemical Reference Data, vol. 38, no. 4, pp. 1013-1092, 2009.

[21] P. B. Johnson and R. W. Christy, "Optical constants of the noble metals," Physical Review B: Condensed Matter and Materials Physics, vol. 6, no. 12, pp. 4370-4379, 1972.

[22] P. Giannios, S. Koutsoumpos, K. G. Toutouzas, M. Matiatou, G. C. Zografos, and K. Moutzouris, "Complex refractive index of normal and malignant human colorectal tissue in the visible and near-infrared," Journal of Biophotonics, vol. 10, no. 2, pp. 303310, 2017.

[23] P. Giannios, K. G. Toutouzas, M. Matiatou et al., "Visible to near-infrared refractive properties of freshly-excised humanliver tissues: Marking hepatic malignancies," Scientific Reports, vol. 6, Article ID 27910, 2016.

[24] N. Jiménez-Mancilla, G. Ferro-Flores, C. Santos-Cuevas et al., "Multifunctional targeted therapy system based on $99 \mathrm{mTc} /$ 177Lu-labeled gold nanoparticles-Tat(49-57)-Lys3-bombesin internalized in nuclei of prostate cancer cells," Journal of Labelled Compounds and Radiopharmaceuticals, vol. 56, no. 13, pp. 663-671, 2013.

[25] C. Holmer, K. S. Lehmann, J. Risk et al., "Colorectal tumors and hepatic metastases differ in their optical properties - Relevance for dosimetry in laser-induced interstitial thermotherapy," Lasers in Surgery and Medicine, vol. 38, no. 4, pp. 296-304, 2006. 

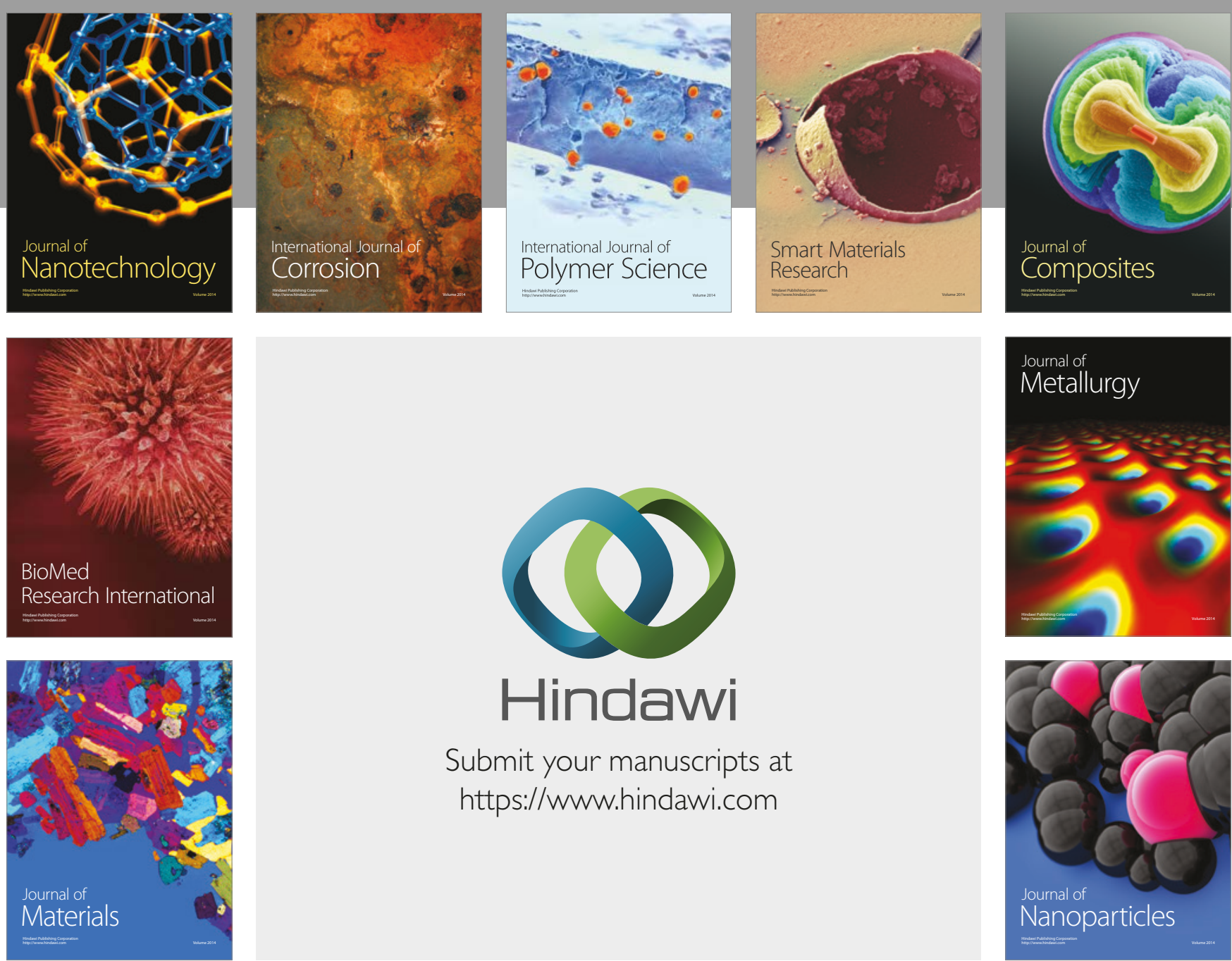

\section{Hindawi}

Submit your manuscripts at

https://www.hindawi.com
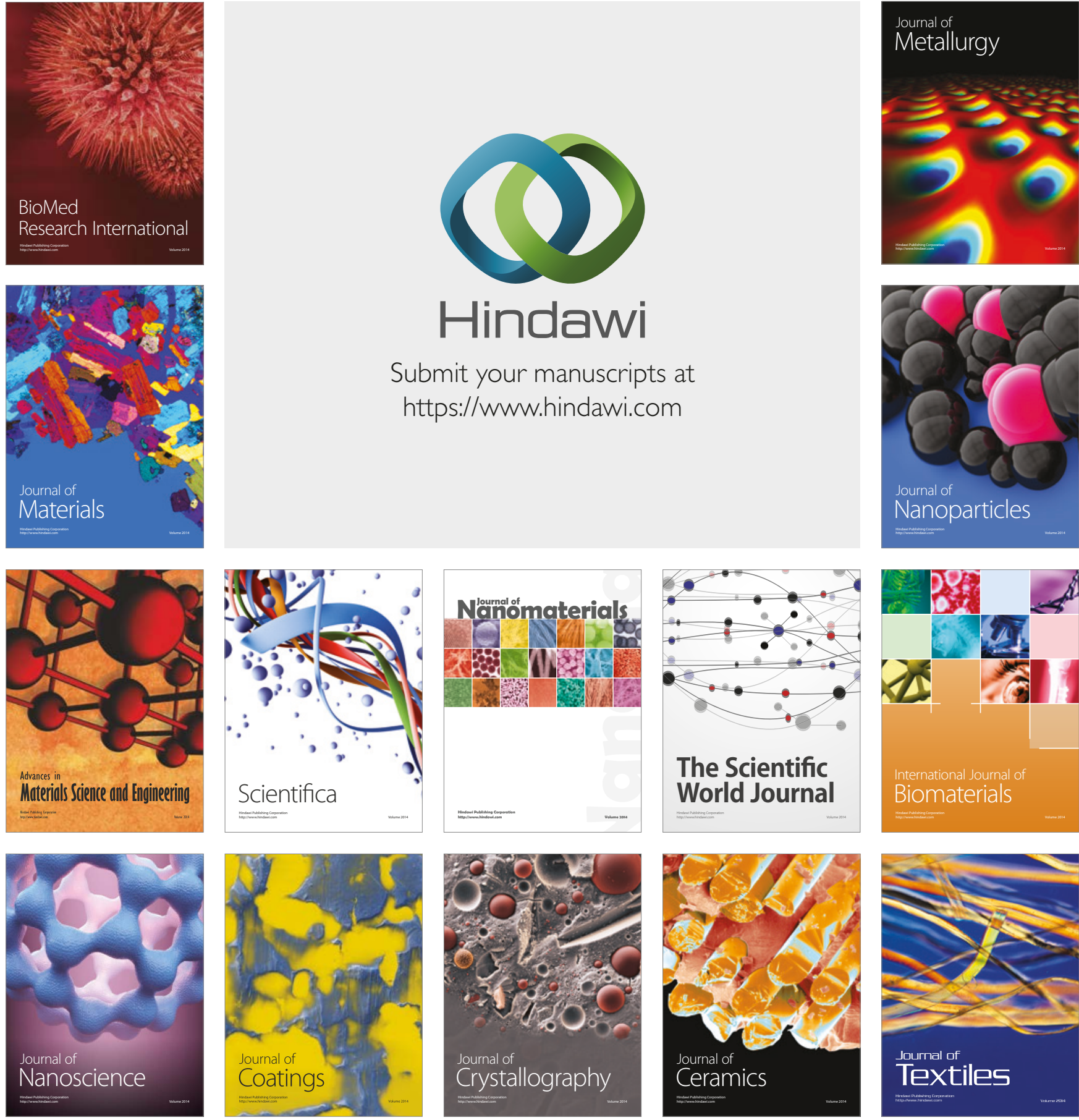

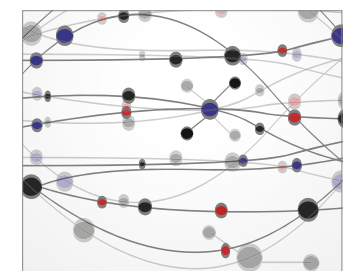

The Scientific World Journal
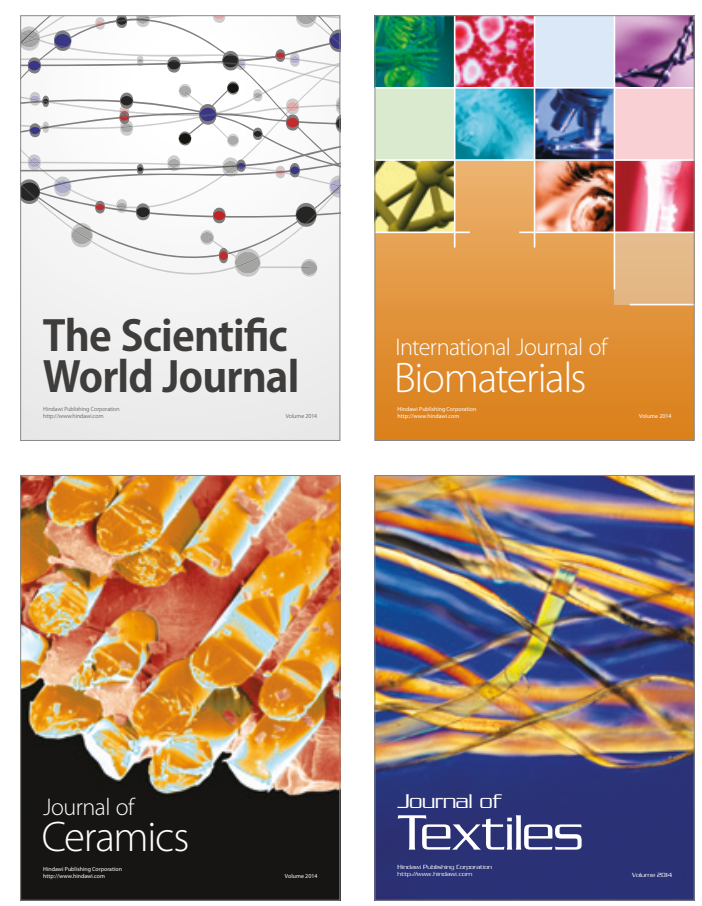